\title{
Cross-protective effect of a combined L5 plus L3 Leishmania major ribosomal protein based vaccine combined with a Th1 adjuvant in murine cutaneous and visceral leishmaniasis
}

Laura Ramirez', Laura Corvo', Mariana C Duarte², Miguel A Chávez-Fumagalli², Diogo G Valadares³, Diego M Santos ${ }^{4}$, Camila I de Oliveira ${ }^{4}$, Marta R Escutia ${ }^{5}$, Carlos Alonso ${ }^{1}$, Pedro Bonay ${ }^{1}$, Carlos AP Tavares ${ }^{3}$, Eduardo AF Coelho ${ }^{2,6+}$ and Manuel Soto ${ }^{1 *+}$

\begin{abstract}
Background: Two Leishmania major ribosomal proteins $L 3(L m L 3)$ and $L 5(L m L 5)$ have been described as protective molecules against cutaneous leishmaniasis due to infection with L. major and Leishmania braziliensis in BALB/c mice when immunized with a Th1 adjuvant (non-methylated CpG-oligodeoxynucleotides; CpG-ODN). In the present study we analyzed the cross-protective efficacy of an LmL3-LmL5-CpG ODN combined vaccine against infection with Leishmania amazonensis and Leishmania chagasi (syn. Leishmania infantum) the etiologic agents of different clinical forms of human leishmaniasis in South America.

Methods: The combined vaccine was administered subcutaneously to BALB/C mice. After immunization the cellular and humoral responses elicited were analyzed. Mice were independently challenged with $L$. amazonensis and $L$. chagasi. The size of the cutaneous lesions caused by the infection with the first species, the parasite loads and the immune response in both infection models were analyzed nine weeks after challenge.

Results: Mice vaccinated with the combined vaccine showed a Th1-like response against $L m L 3$ and $L m L 5$. Vaccinated mice were able to delay lesion development due to L. amazonensis infection and to control parasite loads in the site of infection. A reduction of the parasite burden in the lymph nodes draining the site of infection and in the liver and spleen was observed in the vaccinated mice after a subcutaneous infection with L. chagasi. In both models of infection, protection was correlated to parasite antigen-specific production of IFN- $\gamma$ and down-regulation of parasite-mediated $\mathrm{IL}-4$ and IL-10 responses.
\end{abstract}

Conclusions: The data presented here demonstrate the potential use of L. major $L 3$ and $L 5$ recombinant ribosomal proteins for the development of vaccines against various Leishmania species.

Keywords: Leishmania parasites, L3 and L5 ribosomal proteins, BALB/C mice, Experimental infection, Vaccines, Visceral leishmaniasis, Cutaneous leishmaniasis

\footnotetext{
*Correspondence: msoto@cbm.uam.es

${ }^{\dagger}$ Equal contributors

${ }^{1}$ Centro de Biología Molecular Severo Ochoa (CSIC-UAM), Departamento de Biología Molecular. Nicolás Cabrera 1, Universidad Autónoma de Madrid, 28049 Madrid, Spain

Full list of author information is available at the end of the article
} waiver (http://creativecommons.org/publicdomain/zero/1.0/) applies to the data made available in this article, unless otherwise stated. 


\section{Background}

Infection with different species from the genus Leishmania can cause a variety of clinical symptoms known globally as leishmaniasis [1]. Although some veterinary vaccines against leishmaniasis are now available [2-4] no vaccine has been developed for humans. During the last few years some advances in the development of vaccines against leishmaniasis have been carried out [5]. Given that first generation vaccines using crude parasite antigens were unable to induce protection [6] two main strategies have been explored for the development of anti-Leishmania vaccines. The first one employ live vaccines composed of molecularly modified attenuated parasites (leishmanization) to induce protective anti-Leishmania immune responses $[7,8]$. Alternatively, second generation vaccines are based on the use of parasite protein fractions $[9,10]$ or individual parasite antigens [11]. Although some of these second generation vaccines are currently used in human clinical trials [12] the screening of new candidates will help to further increase the prophylactic efficacy of a Leishmania vaccine. It has been proposed that combination of different parasite antigens may help to attain a vaccine containing the most appropriate protective characteristics [5]. In addition, since multiple Leishmania species are distributed in the same or adjacent geographical regions [13] it would be desirable to develop vaccines containing candidates capable of inducing protection against the infection caused by various Leishmania species. One example of this situation is South America where the leishmaniasis disease ranges from visceral forms (VL) caused by Leishmania chagasi (syn. Leishmania infantum [14]) infection, to cutaneous forms (CL) caused by infection with different parasite species such as Leishmania braziliensis, Leishmania. pifanoi and Leishmania amazonensis. All these species can coexist in different geographical regions [13]. Thus, to be effective as a human vaccine against leishmaniasis its components should be shared by different parasite species and, prior to its use in humans, the protective efficacy of these candidates should be analyzed in different models of experimental leishmaniasis.

Examples of such vaccine preparations are those based on parasite ribosomal proteins. It has been demonstrated that a preparation of biochemically purified Leishmania ribosomal proteins (LRP) administered in combination with Th1 inducing adjuvants conferred protection against the challenge with different parasite species: L. amazonensis and L. chagasi [15] or L. major promastigotes [16]. Also, vaccinated and protected $\mathrm{BALB} / \mathrm{c}$ mice were able to control the disease due to a secondary parasite challenge [17]. It was recently reported that two of the large subunit constituents of L. major ribosomes L3 or L5, expressed as recombinant proteins (LmL3 and LmL5) and administered independently or in combination (always in the presence of a Th1 adjuvant such as non- methylated CpG-oligodeoxynucleotides; CpG-ODN) were able to control the outcome of infection in an experimental model of American CL, namely BALB/c mice infected with L. braziliensis [18]. Globally, it was found that protection was associated with both, the induction of LRP-, LmL3- or LmL5-specific IFN- $\gamma$ mediated responses and the control of the antigen dependent production of the susceptibility associated cytokines IL-10 and IL-4 [19].

The first objective of the study was to analyze the immunogenic properties of a vaccine combining the LmL3 and LmL5 recombinant proteins and CpG-ODN as adjuvant in BALB/c mice. The second objective was to study the combined vaccine prophylactic properties, challenging immunized mice with two different Leishmania species: L. amazonensis and L. chagasi. The potential mechanism of the combined vaccine-induced observed protection was also investigated and is consistent with the maintenance of the Th1-like response against the LmL3 and LmL5 antigens induced by vaccination after infection.

\section{Methods}

\section{Antigens and adjuvant}

Soluble Leishmania antigenic (SLA) extract was prepared from stationary-phase promastigotes of $L$. major, $L$. chagasi and L. amazonensis as previously described [20]. L. major ribosomal proteins (LRP) or mouse ribosomal proteins (MRP) were prepared from logarithmic-phase promastigotes of L. major and RAW 264.7 murine macrophage cells, respectively, as previously described in [10].

LmL3 and LmL5 recombinant proteins were overexpressed in Escherichia coli (M15 strain), purified under denaturing conditions onto Ni-nitrilotriacetic-acid-agarose columns (Qiagen, Hilden, Germany) and refolded on the affinity column, as described in [21]. Polymyxin-agarose columns (Sigma, St. Louis. MO, USA) were employed to remove residual endotoxin content $(<10 \mathrm{ng}$ of LPS per $1 \mathrm{mg}$ of recombinant protein, measured by the Quantitative Chromogenic Limulus Amebocyte Assay QCL-1000 (BioWhittaker, MD, USA)).

Phosphorothioate-modified CpG-ODN (5'-TCAACGT TGA-3' and 5' - GCTAGACGTTAGCGT-3') were synthesized by Isogen Life Science B.V. (De Meern, The Netherlands) and employed for their capacity to induce Th1 responses in mice when immunized with different leishmanial antigenic preparations $[16,22]$.

\section{Immunization, challenge infection, cutaneous lesion development and parasite quantitation}

The Bioethical Committee of the Consejo Superior de Investigaciones Científicas (CEEA-11/046) and the Universidad Autónoma de Madrid (CEI 21-443) in Spain and the Animal Use Committee of the Federal University of Minas 
Gerais (CEUA; 047/2009) in Brazil approved the experimental. Mice ( $n=4$ or 5 ) were subcutaneously (s.c.) immunized in their left hind footpads with a mixture of the LmL3 and LmL5 recombinant proteins ( $6 \mu \mathrm{g}$ each) plus 25 $\mu \mathrm{g}$ of each CpG-ODN (combined vaccine). As control groups, mice ( $n=4$ or 5 ) were inoculated with $25 \mu$ g of each CpG-ODN or with saline (PBS; vaccine diluent). Each group was boosted two and four weeks later with the same dose. For challenge, immunized mice were s.c. infected, into the right hind footpad, with $1 \times 10^{7}$ stationary-phase promastigotes of L. chagasi ( $\mathrm{n}=4$, per group) or with $1 \times 10^{6}$ stationary-phase promastigotes of $L$. amazonensis ( $\mathrm{n}=4$ per group). In mice infected with $L$. amazonensis, footpad swelling was measured with a metric caliper (the thickness of the left footpad minus thickness of the right footpad is shown). At week nine post-challenge all animals were sacrificed. For parasite load determination, the footpads of mice infected with $L$. amazonensis were taken and weighed before their individual processing. In addition the whole spleen, liver and the single popliteal lymph node draining the site of infection (DLN, right leg) of mice s.c. infected with $L$. chagasi were collected and independently processed as follows. Samples were mechanically homogenized in complete Schneider's medium (Schneider's medium (Sigma) supplemented with $20 \%$ heat-inactivated fetal bovine serum (FBS, Sigma), $20 \mathrm{mM}$ L-glutamine, $200 \mathrm{U} / \mathrm{ml}$ penicillin, $100 \mu \mathrm{g} / \mathrm{ml}$ streptomycin and $50 \mu \mathrm{g} / \mathrm{ml}$ gentamicin) and filtered using a cell strainer $(70-\mu \mathrm{m}$ pore size). Each homogenized sample tissue was serially diluted in a 96-well flat-bottomed microtiter plate containing the same medium (in triplicates). The number of viable parasites (by mg of tissue for the footpads and by organ in the spleen, liver and DLN) was determined from the highest dilution at which promastigotes could be grown with up to 10 days of incubation at $25^{\circ} \mathrm{C}$ as previously described [23].

\section{Mice and parasites}

Female BALB/c mice (6-8 weeks old) were purchased from Harlan (BCN, Spain) or from the Institute of Biological Sciences, ICB, Federal University of Minas Gerais (Belo Horizonte, Brazil). First, the immunization procedure was carried out using a total number of 15 mice (5 mice immunized with saline, 5 mice immunized with the adjuvant and 5 mice immunized with the combined vaccine). Mice were euthanized one month after the last immunization for the analysis of the immune response elicited by vaccination. Next, mice were immunized subcutaneously with the combined vaccine $(n=12)$, with the vaccine diluent $(\mathrm{n}=12)$ or with the vaccine adjuvant $(\mathrm{n}=12)$. One month after vaccination, 4 mice per group were euthanized to test the reproducibility of the vaccine induced response. The remaining animals were infected s.c. with L. amazonensis ( $\mathrm{n}=4$ mice per group) or L. chagasi ( $\mathrm{n}=4$ per group) to analyze the effect of vaccination in leishmaniasis progression. This last assay was reproduced using the same number of mice.

Regarding parasites, L. major clone V1 (MHOM/IL/80/ Friedlin), L. chagasi (MOM/BR/1970/BH46) and $L$. amazonensis (IFLA/BR/1967/PH-8) parasites were grown at $25^{\circ} \mathrm{C}$ in complete Schneider's medium.

\section{Cytokine production}

Spleen cells obtained from each mouse were seeded and independently cultured in RPMI complete medium at $5 \times 10^{6}$ cells per ml (RPMI medium (Sigma) supplemented with $10 \%$ heat-inactivated FBS, $20 \mathrm{mM}$ L-glutamine, 200 $\mathrm{U} / \mathrm{ml}$ penicillin, $100 \mu \mathrm{g} / \mathrm{ml}$ streptomycin and $50 \mu \mathrm{g} / \mathrm{ml}$ gentamicin) during $48 \mathrm{~h}$ at $37^{\circ} \mathrm{C}$ in $5 \% \mathrm{CO}_{2}$ alone or with some of the next stimuli: recombinant LmL3 $(12 \mu \mathrm{g} / \mathrm{ml})$, recombinant LmL5 $(12 \mu \mathrm{g} / \mathrm{ml})$, SLA (from the indicated species, $12 \mu \mathrm{g} / \mathrm{ml})$, LmLRP $(12 \mu \mathrm{g} / \mathrm{ml})$ and MRP $(12 \mu \mathrm{g} / \mathrm{ml})$. The release of IFN- $\gamma$, IL-10 and IL-4 was measured in culture supernatants by sandwich ELISA using monoclonal antibodies specific for mouse cytokines (capture and detection) provided in commercial kits (Pharmingen, San Diego, CA, USA), following the manufacturer's instructions.

\section{Analysis of the humoral responses}

Animals ( $n=4$ per group) were bled four weeks after the last immunization and nine weeks after challenge and the anti-LmL3-, anti-LmL5- or anti-SLA specific IgG1 and IgG2a antibodies present in the sera were measured by ELISA, as described elsewhere [20]. Briefly, 96-well plates (Becton Dickinson, Franklin Lakes, NJ, USA) were sensitized with the recombinant proteins or SLA (from the indicated species) at $10 \mu \mathrm{g} / \mathrm{ml}$ (each one) in PBS $(100 \mu \mathrm{l} /$ well $)$ for $16 \mathrm{~h}$ at $4^{\circ} \mathrm{C}$. Plates were blocked with PBS-10\% bovine serum albumin at $37^{\circ} \mathrm{C}$ for $1 \mathrm{~h}$ and treated with $1 / 200$ dilutions of mouse serum samples for $2 \mathrm{~h}$ at $37^{\circ} \mathrm{C}$. Peroxidase-conjugated anti-mouse IgG1 or IgG2a isotype (Sigma) was diluted at 1:5,000 (for recombinant proteins) or 1:10,000 (for SLA) and added for $1 \mathrm{~h}$ at $37^{\circ} \mathrm{C}$. Reactions were developed by incubation with $\mathrm{H}_{2} \mathrm{O}_{2}$ and $\mathrm{O}$-phenylenediamine. Optical densities were read at 492 nanometers in a spectrophotometer (Molecular Devices, Spectra Max Plus, Concord, Canada).

\section{Statistical analysis}

Statistical analysis with the vaccinated and infected mice was performed by a two-tailed Student's $t$-test. Differences were considered significant when $P<0.05$.

\section{Results and discussion}

Immunogenicity of the LmL3 + LmL5 + CpG-ODN combined vaccine in $B A L B / c$ mice

Since combination of different parasite protective antigens have been defined as an adequate strategy for Leishmania vaccine development $[24,25]$ we decided to 
test a LmL3 + LmL5 + CpG-ODN combined vaccine based on the observation that both proteins were able to induce protection against murine $\mathrm{CL}$ due to $L$. major infection [19]. Moreover, administration of the CpG-ODN adjuvant combined with these antigens as single or combined vaccines induced a robust protection in mice against infection with a mixture of $L$. braziliensis stationary-phase promastigotes and insect vector saliva, while no protection was observed when animals were only treated with CpG-ODN [19]. However, the immune response elicited against the antigens by their co-administration was not analyzed in that work.

From an immunological point of view, we show that spleen cells from mice immunized with the combined vaccine were able to secrete LmL3- and LmL5-specific IFN- $\gamma$, since significantly higher levels of this cytokine were found in the culture supernatants after stimulation with these antigens, when compared with the culture supernatants established from control mice, namely saline $(P=0.0006$ for LmL3 and $P=0.0002$ for LmL5) and CpGODN groups $(P=0.0002$ for both antigens) (Figure 1A). The presence of the CpG-ODN, an agonist of the TLR9 [26] that confers a Th1-related long-term immunity and protection when combined with different leishmanial antigens [22] was essential for the stimulation of the antigen specific IFN- $\gamma$ response, since low levels of this cytokine were produced when the LmL3 + LmL5 proteins were coadministered in the absence of the adjuvant (not shown).

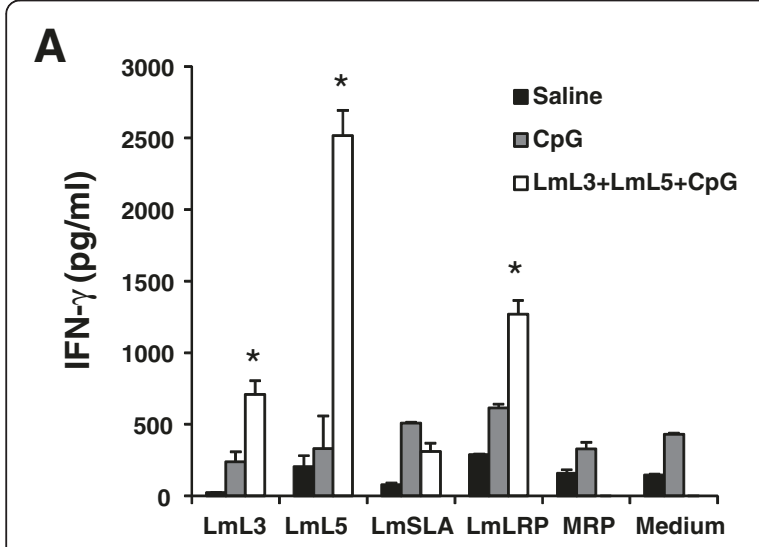

B
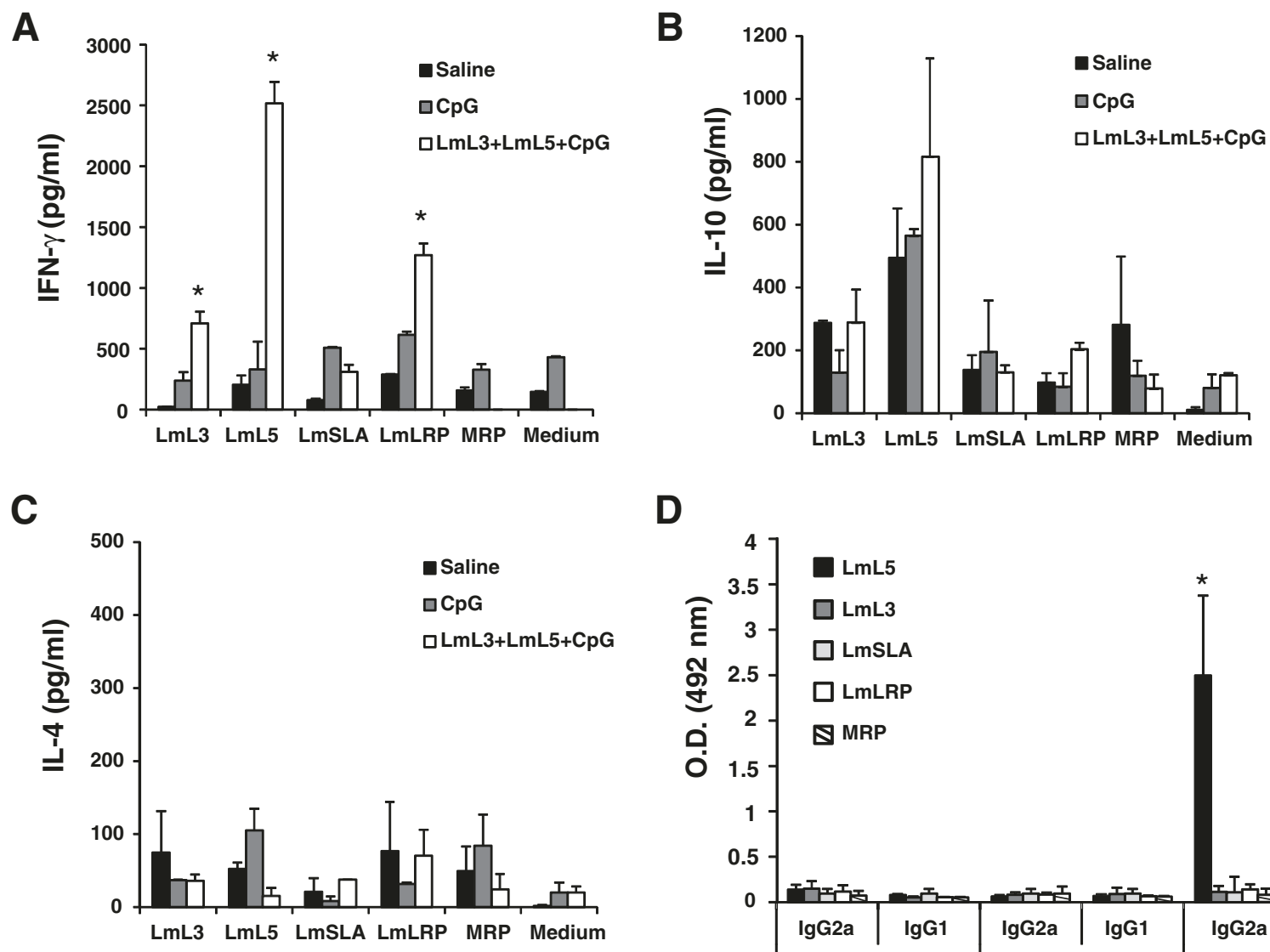

D

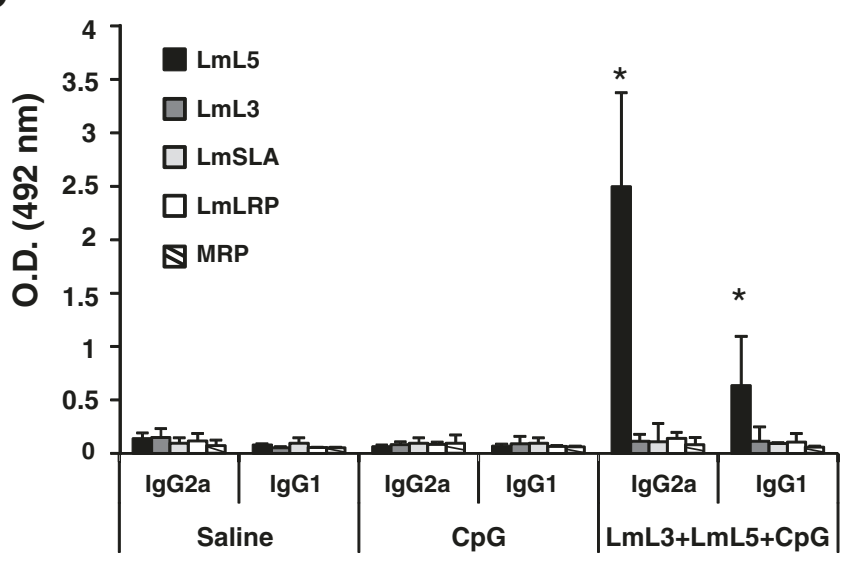

Figure 1 Cellular and humoral responses in BALB/c mice immunized with the $\mathrm{LmL} 3+\mathrm{LmL} 5+\mathrm{CpG}-\mathrm{ODN}$ combined vaccine. Spleen cell cultures were established four weeks after the last vaccine dose and maintained for $48 \mathrm{~h}$ at $37^{\circ} \mathrm{C}, 5 \% \mathrm{CO}_{2}$. As control, spleen cell cultures from mice immunized with the vaccine diluent (Saline) and the $\mathrm{CpG}-\mathrm{ODN}$ adjuvant $(\mathrm{CpG}$ ) were prepared at the same time. Splenocytes were grown without stimulus (medium; background control) or independently stimulated with the recombinant LmL3 or LmL5 proteins (at $12 \mu \mathrm{g} / \mathrm{ml}$ each one), with Soluble L. major Antigen (LmSLA), L. major Ribosomal Proteins (LmLRP) or Mouse Ribosomal Proteins (MRP) (at $12 \mu \mathrm{g} / \mathrm{ml}$ for each extract). (A) IFN- $\gamma$, (B) IL-10 and (C) IL-4 levels were assessed by ELISA in culture supernatants. Each bar represents the mean + standard deviation (SD) of data from five individual mice. ${ }^{*} P<0.05$; significant cytokine production increase between $L \mathrm{~mL} 3+\mathrm{LmL} 5+C p G-O D N$ vaccinated mice and both control groups. (D) IgG1 and IgG2a antibodies against LmL3, LmL5, SLA, LRP and MRP were measured in serum samples from the three mice groups. Samples were obtained four weeks after the last vaccine dose and individually tested by ELISA at 1/200 dilution. Each bar represents the mean $+S D$ of data from five individual mice. ${ }^{*} P<0.05$; significant increase in the optical density between $L m L 3+L m L 5+C p G-O D N$ vaccinated mice and both control groups. Data shown are representative of at least two independent experiments with similar results. 
The IFN- $\gamma$ mediated response was comparable to that induced when each one of the antigens was administered in the presence of the same adjuvant [19]. The LmL3 and LmL5 combined vaccine also induced similar patterns of IL-10 and IL-4 secretion than single based vaccines [19]. Spleen cells from vaccinated mice showed a slightly higher production of IL-10 than control mice groups when stimulated with LmL5, although the differences were not significant (Figure 1B). Very low similar levels of IL-4 were detected in vaccinated and control groups after stimulation with both recombinant proteins (Figure 1C). In addition, vaccinated mice showed a specific anti-LmL5 humoral response that was predominantly of the IgG2a isotype $(P=0.01$ compared with saline and CpG-ODN groups) although IgG1 antibodies specific for this antigen were also observed in the sera from immunized mice $(P=0.03$ compared with saline and CpG-ODN groups) (Figure 1D). It can be concluded that the vaccine combining LmL3, LmL5 and CpG-ODN induced a predominant Th1-like response for both antigens of different magnitude, stronger for LmL5 than for LmL3, because of the robust production of LmL5-specific IFN- $\gamma$ and by the presence of anti-LmL5 IgG2a antibodies, markers of Th1-type responses [27]. The immune response elicited against the recombinant proteins was correlated with a production of IFN- $\gamma$ when $L$. major ribosomes (LmLRP) were employed for in vitro stimulation (Figure 1A; LmLRP). The lack of LmSLA-specific production of cytokines (Figure 1A-C; LmSLA) may be related to the lower contents of ribosomal proteins in a total parasite extract when compared to the LmLRP preparation.

Leishmania LmL3 and LmL5 proteins were selected for a cross-protection analysis due to their high degree of conservation among different Leishmania species [19]. On the other hand, and regarding host counterparts, $L$. major LmL3 and LmL5 showed lower identity and similarity scores with respect to their mouse homologs: Mus musculus L3 (NCBI: NP_038790.2), identity: 59.4\%, similarity: 74.0\%; Mus musculus L5 (NCBI: NP_000960.2), identity: $53.4 \%$, similarity: $68.5 \%$. Remarkably, no humoral or cellular responses against host ribosomal proteins were observed in vaccinated mice (Figure 1A-D; MRP). This lack of immune cross-reactivity between parasite and host intracellular proteins belonging to conserved families was also observed for other intracellular antigens, such as histones and heat shock proteins in infected individuals [28]. This observation has been related to the location of $\mathrm{B}$ and $\mathrm{T}$ cell epitopes in the most divergent regions of these parasite proteins [28-30].

\section{Effects of vaccination in the development of $\mathrm{CL}$ due to} L. amazonensis and VL due to $L$. chagasi in BALB/c mice Since the development of vaccines against leishmaniasis requires the definition of potential candidates capable of inducing protective responses against different Leishmania species [12], we evaluated the protective efficacy of the combined vaccine (LmL3 + LmL5 + CpG-ODN) in two different forms of murine leishmaniasis. The first one was a model of infection with a high dose of $L$. amazonensis stationary promastigotes in the footpad of $\mathrm{BALB} / \mathrm{c}$ mice. This highly pathogenic species is able to cause different forms of American Tegumentary leishmaniasis (ATL) and VL in humans and a severe CL in mice [31,32]. Mice immunized with the combined vaccine showed a reduction in the lesion size when compared with control mice groups immunized with saline or with the adjuvant alone (Figure 2A). Differences were significant until nine weeks after infection when compared with saline and until seven weeks when compared with CpG-ODN group (Figure 2A). At the end of the assay (nine weeks after challenge), the parasite burdens found in the infected footpads were lower in vaccinated mice than in both controls groups (Figure 2B).

The decrease in parasite loads in the infected footpads was statistically significant when compared with both groups $\left(P=1.6 \times 10^{-5}\right.$ and $P=4.5 \times 10^{-5}$ for saline and CpG-ODN groups, respectively). It was concluded that although the administration of the adjuvant alone could have a slight influence on the outcome of infection, the administration of the combined vaccine induced a delay of the progressive disease due to the L. amazonensis challenge. The BALB/c-L. amazonensis model of infection has been employed for a limited number of antigenic preparations including some antigens described as protective in other forms of the disease like the LACK protein or the amastigote A2 antigen (reviewed in [11]) and the Leishmania $\mathrm{P} 4$ nuclease, a protein immunogenic in humans infected with L. major [33] and related to protection against experimental murine L. pifanoi infection [34]. Among them, the most protective formulation was based on defined antigens administered in combination with IL12: P4 nuclease [35] or the A2 protein [20], since no footpad swelling was observed after L. amazonensis challenge. Although it is difficult to establish a direct comparison between different vaccine candidates (due to the use of different parasite strains, number of parasite in the inoculum, adjuvants employed, etc.), the combined vaccine assayed here seems to be inducing weaker protection than vaccines that employ IL-12 as adjuvant, a cytokine that plays a central role in promoting Th1 responses and cellmediated immunity [36]. The effects of the combined vaccine are more comparable with other vaccines based on parasite total proteins [37-39], antigenic extracts [38-40] including LRP + saponin [15] and some DNA vaccines based on the A2 [41] or LACK [39] proteins, that induced a delay in the footpad swelling. Of interest, the 4.5-log reduction observed in the footpad parasite loads of mice vaccinated with the $\mathrm{LmL} 3+\mathrm{LmL} 5+\mathrm{CpG}-\mathrm{ODN}$ 


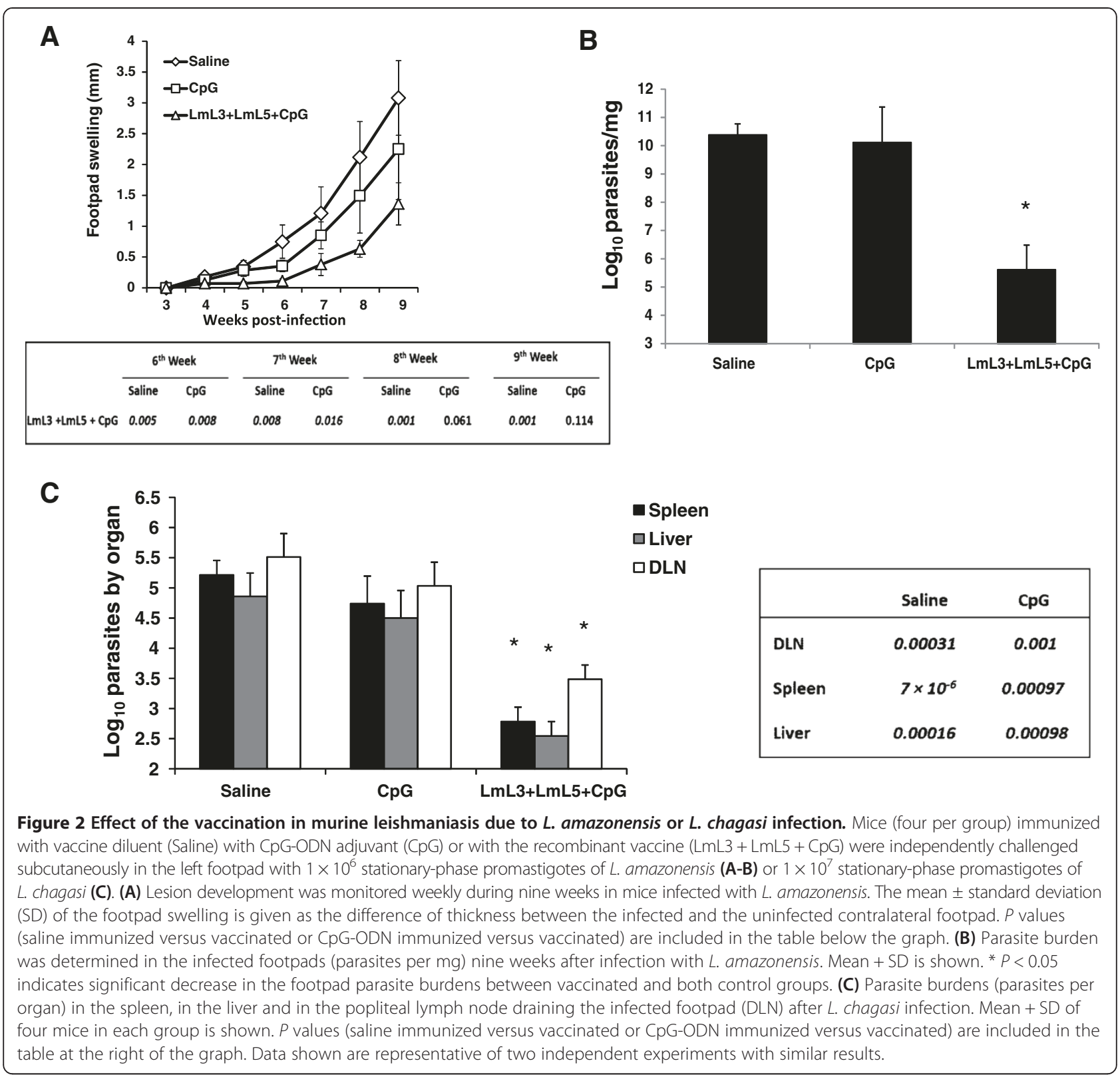

preparation with respect to both control groups (Figure 2B) was comparable in magnitude with parasite burden differences observed in mice vaccinated with the most protective formulations and their controls [20,35,41]. Moreover, it should be taken into account that some antigen-based vaccines, such as LACK combined with IL-12 [20] or a DNA vaccine based on a Nucleoside Hidrolase [41] an antigen that induces partial protection against other Leishmania species [34], were unable to control murine CL due to $L$. amazonensis infection. In addition, some parasite serine-proteases were able to exacerbate the $L$. amazonensis related disease when immunized as a prophylactic preparation alone or combined with saponin [42].
A great number of different molecules have been tested as second generation vaccines in murine models of VL infection [43]. Most of the tested antigens were studied using the intravenous route of infection that guarantee the induction of VL but could undervalue the potential efficacy of some vaccines [44]. We decided to subcutaneously challenge $L$. chagasi in the footpad of BALB/c mice because this model has been accepted as an optimal screening tool to analyze protective antigens [45] and has been previously employed to test the immunoprophylactic properties of different parasite components $[46,47]$, including the combination of LRP and saponin [15]. As it is shown in Figure $2 C$ the $L$. chagasi challenge resulted in parasite active infection with the presence of 
parasites in the DLN (in the absence of footpad swelling) but also in the spleen and in the liver, internal organs involved in parasite replication in murine VL [48]. Nine weeks after infection, mice immunized with LmL3 + LmL5 + CpG-ODN showed significantly lower parasite burdens than both control groups in the three analyzed organ locations (Figure 2C). The decrease of parasite loads in the vaccinated mice was more evident in the internal organs (2.5-log reduction in the liver and in the spleen when compared with saline group and $2-\log$ reduction in the liver and in the spleen when compared with the CpG-ODN group). A significant decrease in the parasite burdens of the lymph node draining the infected footpad (2-log and 1.5-log reduction when compared with saline and CpG-ODN groups, respectively) was also observed. As it also occurred after $L$. amazonensis challenge (the present study) and other cutaneous species (L. major and L. braziliensis [19]) vaccinated mice were able to control the replication of different Leishmania species, allowing the conclusion that LmL3 and LmL5 based vaccines will fit the requirements to a pan-Leishmania vaccine.

\section{Immunological parameters associated with protection}

To determine the immunological parameters of protection, the production of different cytokines in the supernatants of spleen cell cultures, established from the different groups of mice and stimulated with different antigenic preparations was analyzed.

First, the post-infection response against the antigens composing the vaccine was examined. Vaccinated and infected mice showed an IFN- $\gamma$ LmL3- and LmL5specific production that was absent in the infected control groups. A significant increase in the level of this cytokine in the supernatant of vaccinated versus saline and CpG spleen cells cultures was observed after stimulation with LmL3: $P=0.0006$ for both antigens in $L$. amazonensis infected mice (Figure 3A) and $P=0.0008$ and $P=0.0007$, respectively, in $L$. chagasi infected mice (Figure 3B). Similarly, stimulation with LmL5 resulted in the secretion of higher levels of IFN- $\gamma$ in vaccinated than in saline and CpG control mice groups: $P=0.0008$ for both antigens in $L$. amazonensis infected mice (Figure 3A) and $P=2 \times 10^{-5}$ and $P=3 \times 10^{-5}$, respectively, in L. chagasi infected mice (Figure 3B). We did not detect antigen specific IL-4 or IL-10 production after stimulation with the recombinant LmL3 or LmL5 proteins in the vaccinated and infected mice. Thus, it was concluded that after challenge the Th1-like response elicited against the LmL3 and LmL5 ribosomal proteins by the vaccine was maintained. Following infection, cellular responses elicited against LmL5 were higher than those detected against LmL3. The different immunogenic properties of the two recombinant proteins were also observed in the humoral responses elicited against both proteins in the infected mice. In both mouse models, L. amazonensis vaccinated and infected mice (Figure 4A) or L. chagasi vaccinated and infected mice (Figure $4 \mathrm{~B}$ ) the reactivity against LmL5 was stronger than against LmL3, as also occurred in mice vaccinated with these proteins after L. major infection [19]. In the L. amazonensis model higher IgG2a anti-LmL3 and antiLmL5 antibody reactivity were observed in vaccinated than in saline mice groups $(P=0.0063$ and $P=0.0006$, respectively) or in $\mathrm{CpG}-\mathrm{ODN}$ immunized mice $(P=$ 0.002 and $\mathrm{P}=0.001$, respectively) (Figure $4 \mathrm{~A}$ ). After $L$. chagasi infection only the IgG2a anti-LmL5 antibodies showed higher reactivity in vaccinated than in control mice $(P=0.002$ saline and $\mathrm{P}=0.003 \mathrm{CpG-ODN})$ (Figure 4B).

The systemic cellular response in infected BALB/c mice against $L$. amazonensis parasite total proteins was analyzed by LaSLA (prepared from this parasite specie) stimulation of spleen cell cultures established from saline and CpG-ODN control groups. SLA specifically induced the secretion of IL-4 and IL-10 production in the absence of IFN- $\gamma$ production in both infected control groups (Figure $3 \mathrm{~A}$ ). This low $\mathrm{T}$ - cell response also reported for other experimental infections performed with L. amazonensis $[15,20,41,49]$ can negatively affect the activation of the effector functions of macrophages for destroying the intracellular amastigotes [31,50]. On the contrary, after infection vaccinated mice mounted a LaSLA-specific IFN- $\gamma$ mediated response (vaccinated mice versus saline $[P=0.0005]$ or CpG-ODN $[P=$ 0.0006] groups) (Figure $3 \mathrm{~A}$ ), that may be activating the macrophages for destruction of parasites at the infection site, resulting in the observed decrease of the parasite load shown in Figure 2B. As reported here, induction of parasite specific IFN- $\gamma$ responses by vaccination was also related to protection induced by parasite lysates $[15,38,39]$ or single parasite proteins based vaccines $[35,39]$. In addition, a decrease in the LaSLA-mediated IL-4 and IL-10 responses was observed in the vaccinated and infected mice (Figure 3A). A comparison between saline and CpG-ODN controls and protected mice revealed that spleen cells from vaccinated mice produced significantly lower amounts of IL-4 $\left(P=2 \times 10^{-5}\right.$ and $P=$ 0.0002 , respectively) and IL-10 $(P=0.002$ and $P=0.0001$, respectively). A decrease in IL-10 was correlated with protection induced by the P4 Hidrolase protein + IL-12 vaccine [35] and a decrease of IL-4 and IL-10 parasitespecific mediated responses was also observed in mice protected by the administration of LRP + saponin [15], although the exact role of these cytokines in the development of lesions due to $L$. amazonensis is not fully understood [31]. The humoral responses elicited against total parasite proteins were in accordance with the 


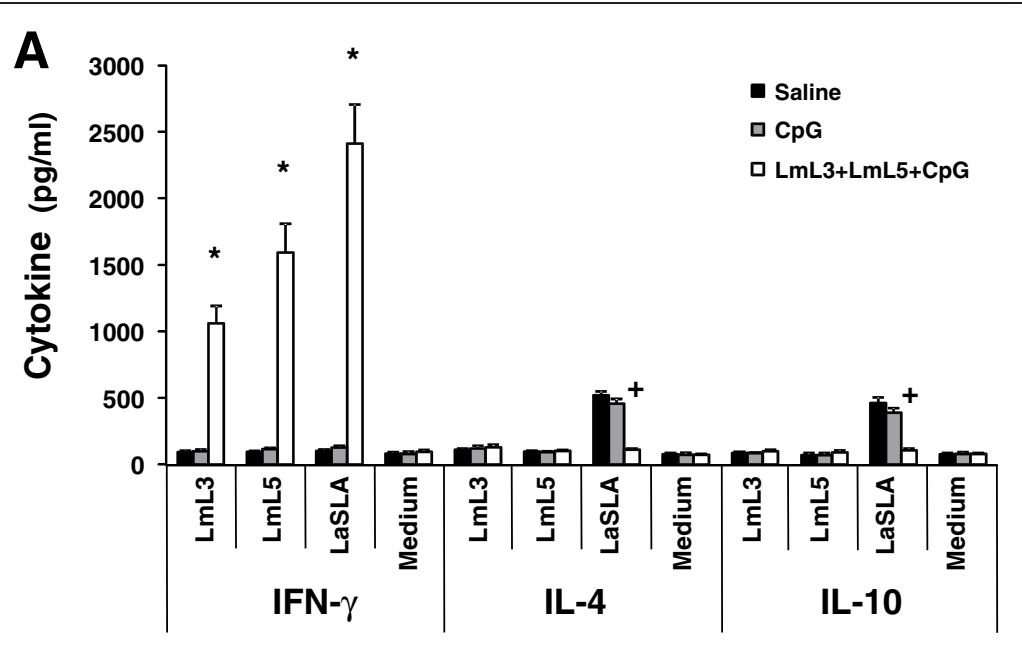

B

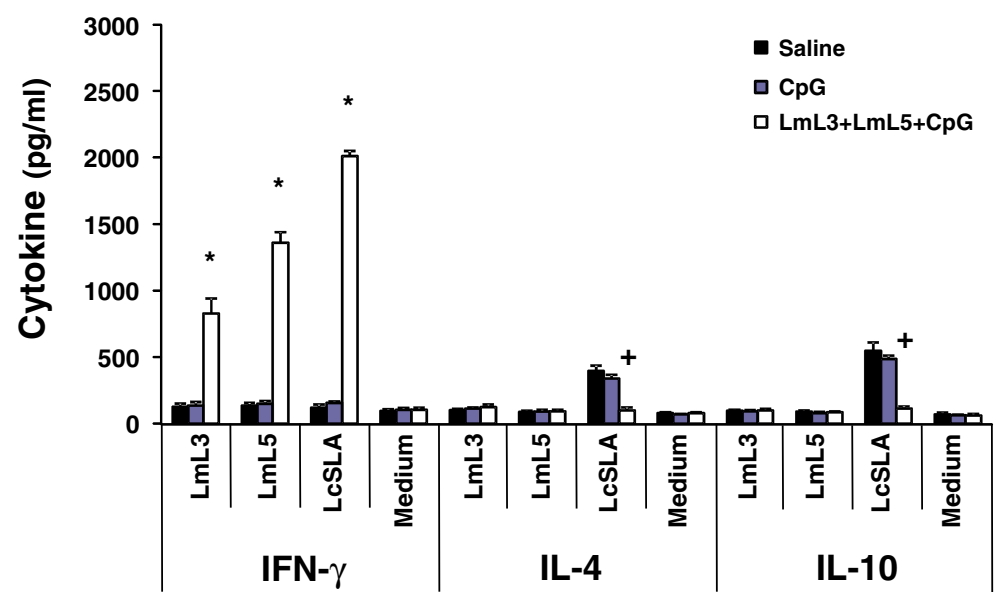

Figure 3 Production of cytokines by spleen cells of vaccinated mice after Leishmania infection. Mice (four per group) immunized with vaccine diluent (Saline), with CpG-ODN adjuvant $(\mathrm{CpG})$ or with the recombinant vaccine $(\mathrm{LmL} 3+\mathrm{LmL} 5+\mathrm{CpG})$ were independently challenged subcutaneously in the left footpad with $1 \times 10^{6}$ stationary- phase promastigotes of L. amazonensis (A) or $1 \times 10^{7}$ stationary-phase promastigotes of L. chagasi (B). Nine weeks after infection, spleen cell cultured suspensions were non-stimulated (Medium; background control) or separately stimulated with recombinant $\mathrm{LmL} 3$ or $\mathrm{LmL} 5(12 \mu \mathrm{g} / \mathrm{ml}$ each one) or with SLA from L. amazonensis (LaSLA; A) or L. chagasi (LCSLA, B) at $12 \mu \mathrm{mg} / \mathrm{ml}$ each one for $48 \mathrm{~h}$ at $37^{\circ} \mathrm{C}, 5 \% \mathrm{CO}_{2}$. IFN- $\gamma$, IL-4 and IL-10 levels were measured in culture supernatants by ELISA. Mean + standard deviation (SD) of cytokine levels determined in four individual mice per group is shown; ${ }^{*} P<0.05$ indicates significant cytokine production increase between $\mathrm{LmL3}+\mathrm{LmL} 5+C p G-O D N$ vaccinated mice and both control groups;,$+ P<0.05$ indicates significant cytokine production decrease between $L \mathrm{~mL} 3$ $+\mathrm{LmL} 5+\mathrm{CpG}-\mathrm{ODN}$ vaccinated mice and both control groups. Data shown are representative of two independent experiments with similar results.

cellular responses induced by infection, since anti-LaSLA antibodies found in the vaccinated mice were mainly of the IgG2a isotype, being the anti-LaSLA reactivity of the IgG1 isotype antibodies significantly lower than those detected in both control groups $(P=0.0006$ versus saline and $P=0.0007$ versus CpG-ODN, respectively) (Figure 5).

Similarly, when the cellular responses elicited in BALB/c mice infected with $L$. chagasi against the LcSLA (using extracts prepared from this parasite specie) were analyzed, a LCSLA-specific production of IFN- $\gamma$ was detected in the vaccinated mice that was absent in saline $\left(P=5 \times 10^{-9}\right)$ or CpG-ODN $\left(P=4 \times 10^{-7}\right)$ groups (Figure 3B). This response was correlated to the predominant presence of anti-LcSLA IgG2a antibodies in the sera from vaccinated and infected mice (Figure 5). Since IFN- $\gamma$ dependent activation of infected macrophages for production of nitric oxide is necessary for Leishmania intracellular killing [51] this cytokine has been considered one of the main factors implicated in the acquired immunity against infection with viscerotropic Leishmania species [15,41,52,53]. IL-10 


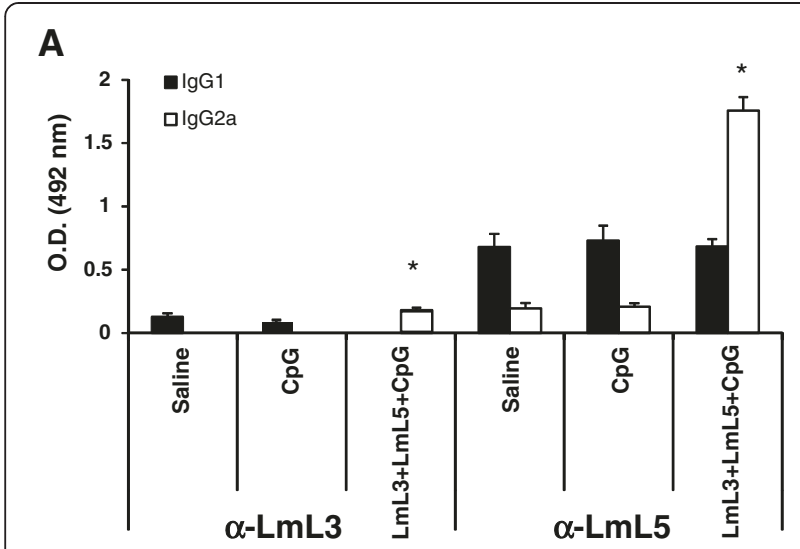

B

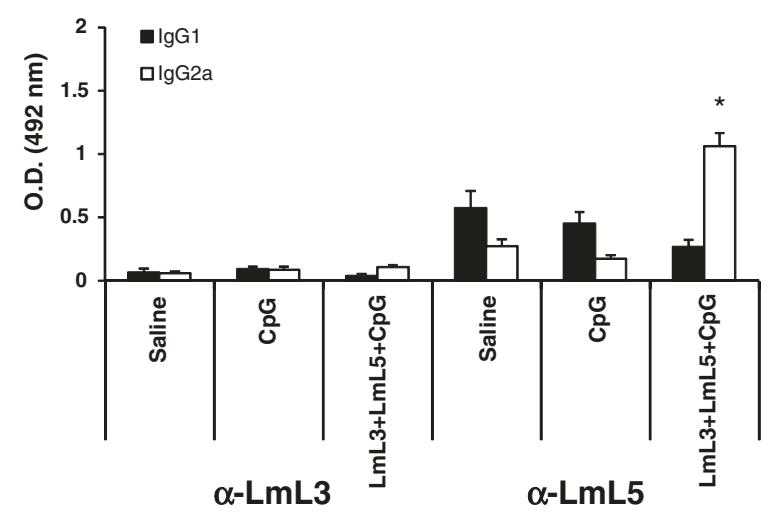

Figure 4 Humoral response against the recombinant antigens following infection with L. amazonensis (A) or L. chagasi (B).

Nine weeks after parasite challenge vaccinated and control mice ( $n=4$ per group) were bled and sera were individually tested by ELISA for specific anti-LmL3 and anti-LmL5 antibody responses of both $\operatorname{lgG1}$ and IgG2a isotype at 1/200 dilution. Each bar represents the mean + standard deviation (SD) of data from four individual mice. * $P<0.05$ indicates significant increase in the optical density between $\mathrm{LmL} 3+\mathrm{LmL} 5+\mathrm{CpG}-\mathrm{ODN}$ vaccinated mice and both control groups. Data shown are representative of two independent experiments with similar results.

parasite mediated responses are critical for VL progression [54], since BALB/c mice lacking the gene for IL-10 [55] or $\mathrm{BALB} / \mathrm{c}$ mice treated with an anti-IL-10 receptor antibody [56] are resistant to infection. In accordance, mice vaccinated with the LmL3 + LmL5 + CpG-ODN combined vaccines showed a specific decrease in the LcSLA-mediated IL-10 ( $P=0.0004$ for saline and $P=8 \times 10^{-7}$ for CpGODN) (Figure $3 \mathrm{~B}$ ) and also a controlled production of IL-4 specific for the parasite antigens $\left(P=7 \times 10^{-5}\right.$ for saline and $P=2 \times 10^{-5}$ for CpG-ODN) (Figure $3 \mathrm{~B}$ ) correlated to the presence of low levels of anti-LcSLA IgG1 reacting antibodies (Figure 5). Although the implication of IL-4 mediated responses in murine VL progression has not been clearly demonstrated, various reports have correlated the induction of protection against a subcutaneous challenge

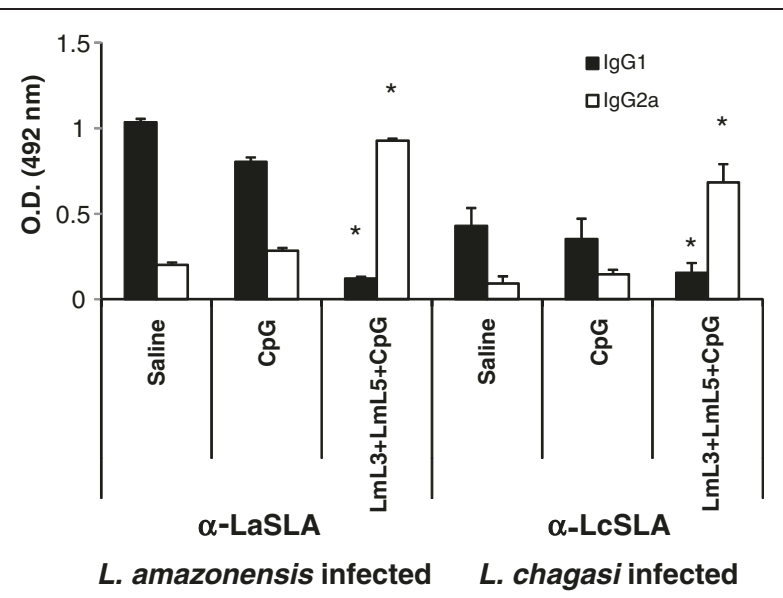

Figure 5 Humoral response against soluble parasite antigens (SLA) antigens following infection with $L$. amazonensis or $L$. chagasi. Nine weeks after parasite challenge vaccinated and control mice ( $n=4$ per group) were bled and sera were individually tested by ELISA for specific anti-SLA antibody responses of both $\lg G 1$ and lgG2a isotypes at 1/200 dilution. Each bar represents the mean + standard deviation (SD) of data from four individual mice. * $P<0.05$ indicates significant changes in the optical density between $L m L 3+L m L 5+C p G-O D N$ vaccinated mice and both control groups. Data shown are representative of two independent experiments with similar results.

with $L$. chagasi to the control of Leishmania-specific IL-4 mediated responses $[15,41,46,47]$.

\section{Conclusions}

The present study indicated that the administration of a vaccine based on the combination of the recombinant versions of the L. major ribosomal proteins L3 and L5 in the presence of a Th1 adjuvant (CpG-ODN) conferred crossprotection in BALB/c mice against subcutaneous infection with two different Leishmania species: L. amazonensis and L. chagasi. After vaccination, mice showed an LmL3, LmL5 and LRP (Leishmania ribosomal proteins) Th1-like response as shown by the production of IFN- $\gamma$ specific for these antigens, in the absence of IL-10 or IL-4-specific responses. In spite of the conserved nature of the ribosomal proteins, vaccinated mice did not show cellular and humoral responses against the ribosomal protein of the vertebrate host (MRP extract). The immune response against LmL3 and LmL5 elicited by the combined vaccine was maintained after infection in the vaccinated and protected mice. Protection was also correlated with the induction of parasite dependent IFN- $\gamma$ responses and with the downregulation of parasite dependent IL-4 and IL-10 responses. Since LmL3 and LmL5 based vaccines were able to induce protection against different Leishmania species in BALB/C mice (L. amazonensis and L. chagasi; this work) and other cutaneous species such as L. major and L. braziliensis [19] we may conclude that these antigens could play a relevant role as components of a pan-Leishmania vaccine. 


\section{Competing interests}

The authors declare that they have no competing interests.

\section{Authors' contributions}

$L R, L C, M C D, M A C F, D G V, M R E$ and MS carried out the experimental procedures. MACF, DMS, CIO, MRE, CA, PB, CAPT, EAFC and MS conceived the research, contributed with data analysis and revised the manuscript. EAFC and MS wrote the manuscript. All authors read and approved the final version of the manuscript.

\section{Acknowledgements}

The study was supported in Spain by grants from Laboratorios LETI S.L.uFundación Severo Ochoa, from Ministerio de Ciencia e Innovación FIS/ PI080101 and FIS PI11/00095 and from the Instituto de Salud Carlos III within the Network of Tropical Diseases Research (VI P I + D + I 2008-2011, ISCIII -Subdirección General de Redes y Centros de Investigación Cooperativa (RD12/0018/0009)). This work was also, in part, supported by grants from Instituto Nacional de Ciência e Tecnologia em Nano-Bbiofarmacêutica, FAPEMIG (CBB-APQ-00496-11 and CBB-APQ-00819-12), and CNPq (APQ-472090/ 2011-9 and APQ-482976/2012-8). EAFC is a grant recipient of CNPq. MACF is a grant recipient of CAPES/FAPEMIG. A CBMSO institutional grant from Fundación Ramón Areces is also acknowledged.

\section{Author details}

${ }^{1}$ Centro de Biología Molecular Severo Ochoa (CSIC-UAM), Departamento de Biología Molecular. Nicolás Cabrera 1, Universidad Autónoma de Madrid, 28049 Madrid, Spain. ${ }^{2}$ Programa de Pós-Graduação em Ciências da Saúde: Infectologia e Medicina Tropical, Faculdade de Medicina, Universidade Federal de Minas Gerais, Belo Horizonte, Minas Gerais, Brazil. ${ }^{3}$ Departamento de Bioquímica e Imunologia, Instituto de Ciências Biológicas, Universidade Federal de Minas Gerais, Belo Horizonte, Minas Gerais, Brazil. ${ }^{4}$ Centro de Pesquisas Gonçalo Moniz, FIOCRUZ, Salvador, Bahia, Brazil. ${ }^{5}$ Research \& Development Department, Laboratorios LETI S.L.u, 28760 Madrid, Spain. ${ }^{6}$ Departamento de Patologia Clínica, COLTEC, Universidade Federal de Minas Gerais, Belo Horizonte, Minas Gerais, Brazil.

Received: 24 September 2013 Accepted: 28 December 2013 Published: 2 January 2014

\section{References}

1. Herwaldt BL: Leishmaniasis. Lancet 1999, 354(9185):1191-1199.

2. Moreno J, Vouldoukis I, Martin V, McGahie D, Cuisinier AM, Gueguen S: Use of a LiESP/QA-21 vaccine (CaniLeish) stimulates an appropriate Th1-dominated cell-mediated immune response in dogs. PLoS Negl Trop Dis 2012, 6(6):e1683.

3. Marcondes M, Ikeda FA, Vieira RF, Day MJ, Lima VM, Rossi CN, Perri SH, Biondo AW: Temporal lgG subclasses response in dogs following vaccination against Leishmania with Leishmune(R). Vet Parasitol 2011, 181(2-4):153-159.

4. Fernandes AP, Coelho EA, Machado-Coelho GL, Grimaldi G Jr, Gazzinelli RT: Making an anti-amastigote vaccine for visceral leishmaniasis: rational, update and perspectives. Curr Op Microbiol 2012, 15(4):476-485.

5. Mutiso JM, Macharia JC, Kiio MN, Ichagichu JM, Rikoi H, Gicheru MM: Development of Leishmania vaccines: predicting the future from past and present experience. J Biomed Res 2013, 27(2):85-102.

6. Handman E: Leishmaniasis: current status of vaccine development. Clin Microbiol Rev 2001, 14(2):229-243.

7. Beattie L, Evans KJ, Kaye PM, Smith DF: Transgenic Leishmania and the immune response to infection. Parasite Immunol 2008, 30(4):255-266.

8. Carrion J, Folgueira C, Soto M, Fresno M, Requena JM: Leishmania infantum HSP70-II null mutant as candidate vaccine against leishmaniasis: a preliminary evaluation. Parasit Vectors 2011, 4:150.

9. Passero LF, Carvalho AK, Bordon ML, Bonfim-Melo A, Carvalho K, Kallas EG, Santos BB, Toyama MH, Paes-Leme A, Corbett CE, et al: Proteins of Leishmania (Viannia) shawi confer protection associated with Th1 immune response and memory generation. Parasit Vectors 2012, 5:64.

10. Iborra S, Parody N, Abanades DR, Bonay P, Prates D, Novais FO, Barral-Netto M, Alonso C, Soto M: Vaccination with the Leishmania major ribosomal proteins plus CpG oligodeoxynucleotides induces protection against experimental cutaneous leishmaniasis in mice. Microbes Infect 2008, 10(10-11):1133-1141.
11. Soto M, Ramirez L, Pineda MA, Gonzalez VM, Entringer PF, de Oliveira Indiani $C$, Nascimento IP, Souza AP, Corvo L, Alonso C, et al: Searching genes encoding Leishmania antigens for diagnosis and protection. Scholar Res Exch 2009, 2009:ID 173039.

12. Beaumier CM, Gillespie PM, Hotez PJ, Bottazzi ME: New vaccines for neglected parasitic diseases and dengue. Trans/ Res 2013, 162(3):144-155

13. Duthie MS, Raman VS, Piazza FM, Reed SG: The development and clinical evaluation of second-generation leishmaniasis vaccines. Vaccine 2012, 30(2):134-141.

14. Mauricio IL, Stothard JR, Miles MA: The strange case of Leishmania chagasi. Parasitol Today 2000, 16(5):188-189.

15. Chavez-Fumagalli MA, Costa MA, Oliveira DM, Ramirez L, Costa LE, Duarte MC Martins VT, Oliveira JS, Olortegi CC, Bonay P, et al: Vaccination with the Leishmania infantum ribosomal proteins induces protection in $\mathrm{BALB} / \mathrm{C}$ mice against Leishmania chagasi and Leishmania amazonensis challenge. Microbes Infect 2010, 12(12-13):967-977.

16. Iborra S, Carrion J, Anderson C, Alonso C, Sacks D, Soto M: Vaccination with the Leishmania infantum acidic ribosomal PO protein plus CpG oligodeoxynucleotides induces protection against cutaneous leishmaniasis in C57BL/6 mice but does not prevent progressive disease in BALB/c mice. Infect Immun 2005, 73(9):5842-5852.

17. Ramirez L, Iborra S, Cortes J, Bonay P, Alonso C, Barral-Netto M, Soto M: $\mathrm{BALB} / \mathrm{c}$ mice vaccinated with Leishmania major ribosomal proteins extracts combined with $\mathrm{CpG}$ oligodeoxynucleotides become resistant to disease caused by a secondary parasite challenge. J Biomed Biotechnol 2010, 2010:181690.

18. de Moura TR, Novais FO, Oliveira F, Clarencio J, Noronha A, Barral A, Brodskyn C, de Oliveira Cl: Toward a novel experimental model of infection to study American cutaneous leishmaniasis caused by Leishmania braziliensis. Infect Immun 2005, 73(9):5827-5834.

19. Ramirez L, Santos DM, Souza AP, Coelho EA, Barral A, Alonso C, Escutia MR, Bonay $\mathrm{P}$, de Oliveira $\mathrm{Cl}$, Soto M: Evaluation of immune responses and analysis of the effect of vaccination of the Leishmania major recombinant ribosomal proteins L3 or L5 in two different murine models of cutaneous leishmaniasis. Vaccine 2013, 31(9):1312-1319.

20. Coelho EA, Tavares CA, Carvalho FA, Chaves KF, Teixeira KN, Rodrigues RC, Charest H, Matlashewski G, Gazzinelli RT, Fernandes AP: Immune responses induced by the Leishmania (Leishmania) donovani A2 antigen, but not by the LACK antigen, are protective against experimental Leishmania (Leishmania) amazonensis infection. Infect Immun 2003, 71(7):3988-3994.

21. Shi PY, Maizels N, Weiner AM: Recovery of soluble, active recombinant protein from inclusion bodies. Biotechniques 1997, 23(6):1036-1038.

22. Rhee EG, Mendez S, Shah JA, Wu CY, Kirman JR, Turon TN, Davey DF, Davis H, Klinman DM, Coler RN, et al: Vaccination with heat-killed Leishmania antigen or recombinant leishmanial protein and CpG oligodeoxynucleotides induces long-term memory $\mathrm{CD}^{+}$and $\mathrm{CD}^{+} \mathrm{T}$ cell responses and protection against Leishmania major infection. J Exp Med 2002, 195(12):1565-1573.

23. Buffet PA, Sulahian A, Garin YJ, Nassar N, Derouin F: Culture microtitration: a sensitive method for quantifying Leishmania infantum in tissues of infected mice. Antimicrob Agents Chemothe 1995, 39(9):2167-2168.

24. Coler RN, Goto Y, Bogatzki L, Raman V, Reed SG: Leish-111f, a recombinant polyprotein vaccine that protects against visceral leishmaniasis by elicitation of CD4+ T cells. Infect Immun 2007, 75(9):4648-4654.

25. Bertholet S, Goto Y, Carter L, Bhatia A, Howard RF, Carter D, Coler RN, Vedvick TS, Reed SG: Optimized subunit vaccine protects against experimental leishmaniasis. Vaccine 2009, 27(50):7036-7045.

26. Ulevitch RJ: Therapeutics targeting the innate immune system. Nat Rev Immunol 2004, 4(7):512-520.

27. Coffman RL: Mechanisms of helper T-cell regulation of B-cell activity. Ann N Y Acad Sci 1993, 681:25-28.

28. Requena JM, Alonso C, Soto M: Evolutionarily conserved proteins as prominent immunogens during Leishmania infections. Parasitol Today 2000, 16(6):246-250.

29. Meddeb-Garnaoui A, Toumi A, Ghelis H, Mahjoub M, Louzir H, Chenik M: Cellular and humoral responses induced by Leishmania histone $\mathrm{H} 2 \mathrm{~B}$ and its divergent and conserved parts in cutaneous and visceral leishmaniasis patients, respectively. Vaccine 2010, 28(7):1881-1886.

30. Probst P, Stromberg E, Ghalib HW, Mozel M, Badaro R, Reed SG, Webb JR: Identification and characterization of T cell-stimulating antigens from Leishmania by CD4 T cell expression cloning. J Immunol 2001, 166(1):498-505. 
31. Soong L: Subversion and Utilization of Host Innate Defense by Leishmania amazonensis. Front Immunol 2012, 3:58.

32. Pereira BA, Alves CR: Immunological characteristics of experimental murine infection with Leishmania (Leishmania) amazonensis. Vet Parasitol 2008, 158(4):239-255.

33. Farajnia S, Mahboudi F, Ajdari S, Reiner NE, Kariminia A, Alimohammadian MH: Mononuclear cells from patients recovered from cutaneous leishmaniasis respond to Leishmania major amastigote class I nuclease with a predominant Th1-like response. Clin Exp Immunol 2005, 139(3):498-505.

34. Soong L, Duboise SM, Kima P, McMahon-Pratt D: Leishmania pifanoi amastigote antigens protect mice against cutaneous leishmaniasis. Infect Immun 1995, 63(9):3559-3566.

35. Campbell K, Diao H, Ji J, Soong L: DNA immunization with the gene encoding P4 nuclease of Leishmania amazonensis protects mice against cutaneous leishmaniasis. Infect Immun 2003, 71(11):6270-6278.

36. Gately MK, Renzetti LM, Magram J, Stern AS, Adorini L, Gubler U, Presky DH: The interleukin-12/interleukin-12-receptor system: role in normal and pathologic immune responses. Annu Rev Immunol 1998, 16:495-521.

37. Calvopina M, Barroso PA, Marco JD, Korenaga M, Cooper PJ, Nonaka S, Hashiguchi Y: Efficacy of vaccination with a combination of Leishmania amastigote antigens and the lipid A-analogue ONO-4007 for immunoprophylaxis and immunotherapy against Leishmania amazonensis infection in a murine model of New World cutaneous leishmaniasis. Vaccine 2006, 24(27-28):5645-5652.

38. Pinto EF, de Mello CM, Rossi-Bergmann B: Interferon-gamma-inducing oral vaccination with Leishmania amazonensis antigens protects $\mathrm{BALB} / \mathrm{C}$ and C57BL/6 mice against cutaneous leishmaniasis. Vaccine 2003, 21(25-26):3534-3541.

39. Pinto EF, Pinheiro RO, Rayol A, Larraga V, Rossi-Bergmann B: Intranasal vaccination against cutaneous leishmaniasis with a particulated leishmanial antigen or DNA encoding LACK. Infect Immun 2004, 72(8):4521-4527.

40. Hernandez MX, Barcante TA, Vilela L, Tafuri WL, Afonso LC, Vieira LQ: Vaccine-induced protection against Leishmania amazonensis is obtained in the absence of IL-12/23p40. Immunol Lett 2006, 105(1):38-47.

41. Zanin FH, Coelho EA, Tavares CA, Marques-da-Silva EA, Silva Costa MM, Rezende SA, Gazzinelli RT, Fernandes AP: Evaluation of immune responses and protection induced by $\mathrm{A} 2$ and nucleoside hydrolase (NH) DNA vaccines against Leishmania chagasi and Leishmania amazonensis experimental infections. Microbes Infect 2007, 9(9):1070-1077.

42. de Matos Guedes HL, Pinheiro RO, Chaves SP, De-Simone SG, Rossi-Bergmann B: Serine proteases of Leishmania amazonensis as immunomodulatory and disease-aggravating components of the crude LaAg vaccine. Vaccine 2010, 28(33):5491-5496.

43. Kedzierski L: Leishmaniasis. Hum Vaccin 2011, 7(11):1204-1214.

44. Ahmed S, Colmenares M, Soong L, Goldsmith-Pestana K, Munstermann L, Molina R, McMahon-Pratt D: Intradermal infection model for pathogenesis and vaccine studies of murine visceral leishmaniasis. Infect Immun 2003, 71(1):401-410

45. Oliveira DM, Costa MA, Chavez-Fumagalli MA, Valadares DG, Duarte MC, Costa LE, Martins VT, Gomes RF, Melo MN, Soto M, et al: Evaluation of parasitological and immunological parameters of Leishmania chagasi infection in BALB/C mice using different doses and routes of inoculation of parasites. Parasitol Res 2012, 110(3):1277-1285.

46. Grenfell RF, Marques-da-Silva EA, Souza-Testasicca MC, Coelho EA, Fernandes AP, Afonso LC, Rezende SA: Antigenic extracts of Leishmania braziliensis and Leishmania amazonensis associated with saponin partially protects BALB/C mice against Leishmania chagasi infection by suppressing IL-10 and IL-4 production. Mem Inst Oswaldo Cruz 2010, 105(6):818-822.

47. Martins VT, Chavez-Fumagalli MA, Costa LE, Canavaci AM, Lage PS, Lage DP, Duarte MC, Valadares DG, Magalhaes RD, Ribeiro TG, et al: Antigenicity and protective efficacy of a Leishmania amastigote-specific protein, member of the super-oxygenase family, against visceral leishmaniasis. PLoS Negl Trop Dis 2013, 7(3):e2148.

48. Kaye PM, Svensson M, Ato M, Maroof A, Polley R, Stager S, Zubairi S, Engwerda CR: The immunopathology of experimental visceral leishmaniasis. Immunol Rev 2004, 201:239-253.

49. Valadares DG, Duarte MC, Ramirez L, Chavez-Fumagalli MA, Lage PS, Martins VT, Costa LE, Ribeiro TG, Regis WC, Soto M, et al: Therapeutic efficacy induced by the oral administration of Agaricus blazei Murill against Leishmania amazonensis. Parasitol Research 2012, 111(4):1807-1816.
50. Soong L, Chang CH, Sun J, Longley BJ Jr, Ruddle NH, Flavell RA, McMahon-Pratt D: Role of CD4+ T cells in pathogenesis associated with Leishmania amazonensis infection. J Immunol 1997, 158(11):5374-5383.

51. Wilson ME, Jeronimo SM, Pearson RD: Immunopathogenesis of infection with the visceralizing Leishmania species. Microb Pathog 2005, 38(4):147-160.

52. Silvestre R, Cordeiro-Da-Silva A, Santarem N, Vergnes B, Sereno D, Ouaissi A: SIR2-Deficient Leishmania infantum induces a defined IFN-gamma/L-10 pattern that correlates with protection. J Immunol 2007, 179(5):3161-3170.

53. Resende DM, Caetano BC, Dutra MS, Penido ML, Abrantes CF, Verly RM, Resende JM, Pilo-Veloso D, Rezende SA, Bruna-Romero O, et al: Epitope mapping and protective immunity elicited by adenovirus expressing the Leishmania amastigote specific A2 antigen: correlation with IFN-gamma and cytolytic activity by CD8+ T cells. Vaccine 2008, 26(35):4585-4593.

54. Awasthi A, Mathur RK, Saha B: Immune response to Leishmania infection. Indian J Med Res 2004, 119(6):238-258.

55. Murphy ML, Wille U, Villegas EN, Hunter CA, Farrell JP: IL-10 mediates susceptibility to Leishmania donovani infection. Eur J Immunol 2001, 31(10):2848-2856.

56. Murray HW, Lu CM, Mauze S, Freeman S, Moreira AL, Kaplan G, Coffman RL: Interleukin-10 (IL-10) in experimental visceral leishmaniasis and IL-10 receptor blockade as immunotherapy. Infect Immun 2002, 70(11):6284-6293.

doi:10.1186/1756-3305-7-3

Cite this article as: Ramirez et al:: Cross-protective effect of a combined L5 plus L3 Leishmania major ribosomal protein based vaccine combined with a Th1 adjuvant in murine cutaneous and visceral leishmaniasis. Parasites \& Vectors 2014 7:3.

\section{Submit your next manuscript to BioMed Central and take full advantage of:}

- Convenient online submission

- Thorough peer review

- No space constraints or color figure charges

- Immediate publication on acceptance

- Inclusion in PubMed, CAS, Scopus and Google Scholar

- Research which is freely available for redistribution

Submit your manuscript at www.biomedcentral.com/submit
C Biomed Central 